\title{
СМЯГЧЕНИЕ И УСИЛЕНИЕ НАКАЗАНИЯ ПРИ ЕГО НАЗНАЧЕНИИ В РОССИЙСКОМ УГОЛОВНОМ ПРАВЕ
}

\begin{abstract}
Аннотация: В статье анализируются правила назначения наказания за преступления, по закону караемые смертной казнью или пожизненным лишением свободы. Рассматривается судебная практика в отношении с иелью выделения подхода к судей к определению наказания. Проводится анализ норм Уголовного кодекса Российской Федераиии а также Уголовно-процессуального кодекса. Рассматриваются вопросы и условия смягчения наказания в связи с назначением наказаний в виде лишения свободы. Рассматриваются вопросы исторического развития норм о смягчения и ужесточения наказаний Методологическую основу составляют совокупность принципов и методов научного анализа. В работе использовалось диалектический, а также частно-научные методы В работе предпринята попытка научно осветить вопросы обязательного смягчения наказания по основаниям, предусмотренным частями 2-5 cm.62 УКРФ. Определяется содержание норм обязательного смягчения и усиления наказания. В процессе иссдедования были выявлены трудности определения содержания норм об обязательном смягчении и усилении наказания вследствии неясного их законодательного изложения. Поэтому попытались сформулировать выводы и предложения о состоянии и перспективах развития правил обязательного смягчения и усиления наказания с учетом последних изменениях законодательства.

Abstract: The article concerns the rules for assigning punishments for the crimes, which according to the law may be punished with death penalty or life sentence. The author analyzes the norms of the Criminal Code of the Russian Federation and the Criminal Procedural Code of the Russian Federation, paying attention to the issues of mitigation of punishment in case when deprivation of freedom (term in prison) is assigned. The author also analyzes the issues of historic development of norms on mitigation and aggravation of punishment. The methodological basis for the study is formed by the combination of principles and methods of scientific analysis. The article uses dialectic and private law methods. The article includes an attempt of scientific analysis of the issues regarding obligatory mitigation of punishments under the provisions of p. 2-5 of Art. 62 of the Criminal Code of the Russian Federation. The author defines the contents of the norms on obligatory mitigation and aggravation of punishment. In the process of study the author singles out the difficulties in understanding of the norms on obligatory mitigation and aggravation of sentence due to lack of clarity in their legislative formulae. The author also attempted to form propositions on the current situation and perspectives for the development of the rules for obligatory mitigation and aggravation of sentence taking into account the latest legislative amendments.
\end{abstract}

Ключевые слова: неоконченное преступление, рецидив, суд присяжных, смертная казнь, отягчающие обстоятельства, смягчающие обстоятельства, обязательное усиление, обязательное смягчение, назначение наказание, конкуренция норм Keywords: attempted crime, recidivism, trial by jury, capital punishment, aggravating circumstances, mitigating circumstances, obligatory aggravation, obligatory mitigation, assigning punishment, conflict of laws.

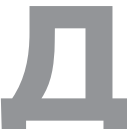

ифференциация уголовной ответственности и индивидуализация наказания проявляются при назначении наказания. На последнее в значительной степени влияют правила обязательных смягчения и усиления наказания.

В УК имеется шесть специальных правил смягчения наказания и три правила - обязательного его усиления. Четыре правила обязательного смягчения предусмотрены в ст. 62 УК, по одному - установлены в ст. 65 и 66 УК. Усиление наказания закреплено в ст. 68,69 и 70 УК.

Все правила по специальному смягчению наказания в обязательном порядке предусматривают его назначение не свыше установленной законом части макси- мального срока или размера наиболее строгого вида наказания, закреплённого санкцией статьи Особенной части УК. Иначе определены в законе правила обязательного усиления наказания. Только в ст. 68 УК содержится норма о вынесении при любом виде рецидива наказания не ниже одной третьей части максимального срока наиболее строгого вида наказания, предусмотренного за совершенное преступление, но в пределах статьи Особенной части УК. В двух других статьях, 69 и 70 УК, назначение наказания по правилам совокупности преступлений или приговоров заключается в соответствующих случаях либо в поглощении более строгим наказания менее строгого, либо в сложении (присоединении) наказаний. 
DOI: 10.7256/1811-9018.2013.12.9942

При цитировании этой статьи сноска на ооі обязательна

\section{Право и политика $12(167) \cdot 2013$}

В ч. 1 ст. 62 УК закреплено назначение наказания при наличии смягчающих обстоятельств, предусмотренных п. «и» и (или) «К» ч. 1 ст. 61 УК, и отсутствии отягчающих обстоятельств на срок или в размере, который не может превышать двух третей максимального срока или размера наиболее строгого вида наказания, предусмотренного статьей Особенной части УК. Данное смягчение наказания возможно как при нескольких, так и одном смягчающем обстоятельстве, предусмотренном или п. «и», и (или) п. «К» ч. 1 ст. 61 УК.

По приговору суда 3. и В. по ч. 1 ст. 115 УК были осуждены к 1 году исправительных работ с удержанием в доход государства из заработной платы $20 \%$. Суд признал обстоятельствами, смягчающими наказание, явку с повинной, активное способствование раскрытию преступления, чистосердечное раскаяние в содеянном. Отягчающих обстоятельств по делу не установлено. Наиболее строгий вид наказания за преступление, предусмотренное ч. 1 ст. 115 УК, - арест, который в действие не введен. Следовательно, наиболее строгим видом наказания являлись исправительные работы, которые были назначены осужденным за указанное преступление.

Однако с применением ч. 1 ст. 62 УК это наказание на момент постановления приговора не должно было превышать 9 месяцев исправительных работ (наказание не свыше трех четвертей максимального срока наиболее строгого наказания, предусмотренного санкцией статьи Особенной части УК). Но в нарушение закона суд назначил осужденным наказание по ч. 1 ст. 115 УК в виде 1 года исправительных работ, что соответствует максимальному размеру этого вида наказания, предусмотренному санкцией статьи.

Приговор в отношении осужденных 3. и В. был изменен: наказание смягчено каждому из них по ч. 1 ст. 115 УК до 6 месяцев исправительных работ с удержанием $20 \%$ заработной платы в доход государства ${ }^{1}$.

Рассматриваемое смягчение невозможно при наличии отягчающего обстоятельства. При этом обстоятельства должны быть отягчающими, а не квалифицирующими или конститутивными (ч. 1 ст. 62 УК). Очевидно, наличие отягчающего обстоятельства не позволяет распространить на лицо, совершившее преступление, рассматриваемую льготу. Данное ограничение можно определить как вполне закономерное: перечень отягчающих обстоятельств по УК исчерпывающий (ст. 63 УК), включает наиболее негативные данные либо о престу-

${ }^{1}$ См.: постановление Президиума Верховного Суда РФ № 215П12пр, 10 апреля 2013 г. // Справочно-информационная система КонсультантПлюс (дата обращения 10 августа 2013 г.). плении, либо о лице, осуществившем посягательство. Присутствие такого отягчающего обстоятельства означает назначение наказания по правилам его усиления, предусмотренным ст. 68 УК.

Заключение досудебного соглашения о сотрудничестве при наличии смягчающих обстоятельств, предусмотренных п. «и» ч. 1 ст. 61 УК, и отсутствии отягчающих обстоятельств, согласно ч. 2 ст. 62 УК, предопределяет назначение наказания на срок или в размере, который не может превышать половины максимального срока или размера наиболее строгого вида наказания, предусмотренного статьей Особенной части УК.

Смягчающего обстоятельства, предусмотренного п. «и» ч. 1 ст. 61 УК, для применения правила о досудебном соглашении о сотрудничестве, установленного ч. 2 ст. 62 УК, достаточно одного. Анализируемое правило смягчения наказания суд применяет при наличии смягчающих обстоятельств, предусмотренных п. «и» ч. 1 ст. 61 УК, и отсутствии отягчающих обстоятельств. Для участников преступлений, совершённых группой, может быть одно отягчающее обстоятельство, закреплённое в п. «в» ч. 1 ст. 63 УК. Это обстоятельство предусматривает совершение преступления в составе группы, группы лиц по предварительному сговору, организованной группы, преступного сообщества. Имеются в виду случаи, когда совершение преступления группой, группой лиц по предварительному сговору, организованной группой, не относится к квалифицирующим признакам, и, соответственно, совершение преступления преступным сообществом не является признаком основного состава преступления. Совершение преступления указанными группами должно быть именно отягчающим наказание обстоятельством. В последнем случае назначение наказания по правилу, предусмотренному ч. 2 ст. 62 УК, невозможно, поскольку имеется отягчающее обстоятельство. Наказание в соответствии с буквой закона следует назначать по общим правилам.

Запрет обязательного смягчения наказания по правилам, предусмотренным ч. 2 ст. 62 УК, при наличии отягчающих обстоятельств учеными оценивается поразному. Так, П.В. Агапов обосновывает необходимость исключения из ч. 2 ст. 62 УК указания на отсутствие отягчающих обстоятельств². На наш взгляд, с этим

\footnotetext{
${ }^{2}$ См.: Агапов П.В. Досудебное соглашение о сотрудничестве как средство повышения эффективности противодействия организованной преступной деятельности // Уголовное право: стратегия развития в XXI веке: материалы IX международной научно-практической конференции (26-27 января 2012). М., 2012. С. 96-97.
} 
предложением можно согласиться. В числе целей принятия анализируемой нормы была необходимость пресечения, а также эффективного раскрытия преступлений, совершенных с участием организованных групп и в целом в соучастии. Совершение преступления в составе организованной группы, согласно п. «в»ч. 1 ст. 63 УК, является отягчающим обстоятельством. Следовательно, если совершение преступления такой группой признается отягчающим обстоятельством, то смягчить наказание в соответствии с рассматриваемым правилом нельзя. Справедливости ради нужно сказать, что чаще всего совершение преступления в составе преступных групп в УК установлено как квалифицирующий или конститутивный признак. В итоге в виде «чистых» отягчающих обстоятельств совершение преступления в составе рассматриваемых групп в реальности незначительно.

В ч. 5 ст. 62 УК установлены две специальные нормы о назначении наказания: при согласии лица с предъявленным обвинением (ст. 316 УПК) и производстве дознания в сокращенной форме (ст. $226^{9}$ УПК). Согласно первой норме наказание назначается лицу, уголовное дело в отношении которого рассмотрено в порядке, предусмотренном главой 40 УПК, когда обвиняемый заявил о согласии с предъявленным ему обвинением (при наличии согласия государственного или частного обвинителя и потерпевшего) на срок или в размере наказания, который не может превышать две трети максимального срока или размера наиболее строгого вида наказания, предусмотренного за совершенное преступление.

В соответствии со ст. 314 УПК такое смягчение применяется при наличии следующих оснований: за преступления, наказание за которые в УК не превышает 10 лет лишения свободы; при наличии согласия обвиняемого с предъявленным ему обвинением; государственный или частный обвинитель и потерпевший согласны с рассмотрением дела в особом порядке.

Указанное обязательное смягчение применяется за совершение преступления небольшой, средней тяжести или тяжкое. Неприменимость положения, закрепленного ч. 5 ст. 62 УК, за особо тяжкое преступление нам представляется закономерной. Рассмотрение дела за совершение последнего необходимо проводить с соблюдением всех процессуальных правил, с судебным разбирательством.

Условиями обязательного смягчения наказания при согласии обвиняемого с предъявленным обвинением (ч. 5 ст. 62 УК) являются заявление ходатайства 1) добровольно; 2) в присутствии защитника; 3) в момент ознакомления обвиняемого с материалами уголовного дела, о чем делается соответствующая запись в протоколе ознакомления с материалами уголовного дела, или на предварительном слушании, когда оно является обязательным.

На последнее условие следует обратить внимание, поскольку во время предварительного следствия возможно появление основания для другого обязательного смягчения наказания: достижения соглашения о сотрудничестве со следствием (ч. 2 ст. 62 УК). В момент же ознакомления обвиняемого с материалами уголовного дела может возникнуть основание для смягчения наказания при согласии обвиняемого с предъявленным ему обвинением (ч. 5 ст. 62 УК).

Последнее обязательное смягчение наказания по правовой природе относится к материальному праву, в связи с чем и основания его применения следует предусмотреть в ч. 5 ст. 62 УК, а не в главе 40 УПК.

В соответствии с ч. 5 ст. 62 УК (ст. $226^{9}$ УПК), срок или размер наказания, назначаемого лицу в случае, указанном в ст. $226^{9}$ УПК, не может превышать одну вторую максимального срока или размера наиболее строгого вида наказания, предусмотренного за совершенное преступление.

Обязательное смягчение наказания применяется по уголовным делам, по которым была соблюдена совокупность определенных условий, предусмотренных ст. 2261-226² УПК, характеризующих 1) лицо, 2) преступление, 3) имеющих отношение к делу ${ }^{3}$.

Условиями, характеризующими лицо, в частности, являются: уголовное дело должно быть возбуждено в отношении конкретного лица; лицо признает свою вину, характер и размер причиненного преступлением вреда, а также не оспаривает правовую оценку деяния, приведенную в постановлении о возбуждении уголовного дела; лицо не является несовершеннолетним; оно владеет языком, на котором ведется уголовное судопроизводство, и другие.

Преступления, за которые возможно производство дознания в сокращенной форме, в соответствии с ч. 3 ст. 150 УПК, должны быть небольшой или средней тяжести.

Потерпевший не возражает против производства дознания в сокращенной форме. Как было указано,

\footnotetext{
${ }^{3}$ См.: «Методические рекомендации по применению органами дознания Федеральной службы судебных приставов дознания в сокращенной форме» (утв. Федеральной службой судебных приставов России 26 апреля 2013 № 04-7) // Справочно-информационная система КонсультантПлюс. Законодательство.
} 
DOI: $10.7256 / 1811-9018.2013 .12 .9942$

При цитировании этой статьи сноска на ооі обязательна

\section{Право и политика $12(167) \cdot 2013$}

только наличие всех этих условий в совокупности позволяет осуществлять дознание в сокращенной форме и, соответственно, быть основанием для смягчения наказания при его назначении.

Правило о наказании при вердикте присяжных заседателей о снисхождении закреплено в ст. 65 УК. Оно состоит в том, что срок или размер наказания лицу, признанному присяжными заседателями виновным в совершении преступления, но заслуживающему снисхождение, не может превышать двух третей максимального срока или размера наиболее строгого вида наказания, предусмотренного за совершенное преступление.

При этом не учитываются отягчающие наказание обстоятельства: председательствующий обязан смягчить наказание, несмотря на наличие даже нескольких отягчающих обстоятельств. «Согласно части 1 статьи 65 и статье 62 УК РФ, определяющим порядок назначения наказания при признании подсудимого заслуживающим снисхождения и при наличии смягчающих обстоятельств, предусмотренных пунктами «и» и «к» части 1 статьи 61 УК РФ, срок и размер наказания исчисляется из срока и размера наиболее строгого вида наказания, предусмотренного санкцией соответствующей статьи Особенной части Уголовного кодекса Российской Федерации. Учитывая это, в случае признания подсудимого заслуживающим снисхождения и при наличии смягчающих обстоятельств, предусмотренных пунктами «и» и «К» части 1 статьи 61 УК РФ» судья обязан назначить такому лицу наказание по правилам, установленным в ст. 65 УК. «Если статьей Особенной части Уголовного кодекса Российской Федерации предусмотрены смертная казнь или пожизненное лишение свободы, эти виды наказаний не применяются, а наказание назначается в пределах санкции, предусмотренной соответствующей статьей Особенной части Уголовного кодекса Российской Федерации. Такой порядок назначения наказания применяется независимо от наличия по делу обстоятельств, отягчающих наказание» ${ }^{4}$.

Если установлен рецидив преступлений, то он как отягчающее обстоятельство не учитывается. Интересно соотношение норм, предусмотренных ч. 1 ст. 62 УК, ст. 65 и 68 УК. При наличии рецидива как отягчающего обстоятельства правила, предусмотренные ч. 1 ст. 62 УК, не применяются. Из оставшихся ст. 65 и 68 УК,

\footnotetext{
${ }^{4}$ Постановление Пленума Верховного Суда Российской Федерации от 22 ноября 2005 г. «О применении судами норм Уголовно-процессуального кодекса Российской федерации, регулирующих судопроизводство с участием присяжных заседателей» (п.42) // БВС РФ. 2006. № 1.
}

положения ст. 68 УК не могут применяться, так как ч. 4 ст. 65 УК запрещает учитывать отягчающие наказание обстоятельства. Применяются правила смягчения наказания, закрепленные ч. 1 ст. 65 УК.

В ч. 2 и 3 ст. 66 УК предусмотрены правила о наказании за неоконченное преступление. За приготовление к преступлению наказание не может превышать половины, а за покушение - трех четвертей максимального срока или размера наиболее строгого вида наказания, предусмотренного соответствующей статьей Особенной части УК за оконченное преступление. Указание на оконченное преступление в рассматриваемых частях ст. 66 УК, по нашему мнению, является лишним. В статьях Особенной части УК названы наказания только за оконченные преступления.

В перечисленных правилах смягчения наказания, исходя из законодательного их содержания и смысла, следует, что суд обязан осуществить данное смягчение. В случаях назначения наказания ниже низшего предела, закреплённого ст. 64 УК, у суда имеется право на его смягчение. В этой связи представляется справедливым мнение о неотнесении правила о назначении наказания более мягкого, чем предусмотрено законом (ст. 64 УК), к правилам обязательного его смягчения ${ }^{5}$.

Вопрос о возможности обязательного смягчения наказания, если статьей Особенной части УК за преступление предусмотрено пожизненное лишение свободы или смертная казнь, для рассматриваемых правил законодатель решил неодинаково.

Правило обязательного смягчения наказания, предусмотренное ч. 1 ст. 62 УК, не применяется, если соответствующей статьей Особенной части УК за преступление предусмотрено пожизненное лишение свободы или смертная казнь. В этом случае наказание назначается в пределах санкции соответствующей статьи Особенной части УК (ч. 3 ст. 62 УК). В санкции предусмотрены три наказания: лишение свободы на определённый срок, пожизненное лишение свободы и смертная казнь. Суд вправе определить и самое строгое из них, в настоящее время таковым является пожизненное лишение свободы ${ }^{6}$.

\footnotetext{
${ }^{5}$ См.: Российское уголовное право. Общая часть / под ред. Л.В.Иногамовой-Хегай, Комиссарова В.С., Рарога А.И. М., 2011. C. 396 .

${ }^{6}$ Смертную казнь нельзя назначить согласно Определению Конституционного Суда РФ от 9 ноября 2010 г. № 536-О-Р «По ходатайству Президиума Верховного Суда Российской Федерации о разъяснении положения пункта 4.3 мотивировочной части Определения Конституционного Суда Российской Федерации от 19 ноября 2009 года № 1344-О-Р о разъяснении пункта 5 резолютивной части Постановления Конституционного Суда Российской
} 
При досудебном соглашении о сотрудничестве, если статьей Особенной части УК за преступление предусмотрены пожизненное лишение свободы или смертная казнь, эти виды наказания не применяются. А срок или размер наказания не может превышать двух третей максимального срока или размера наиболее строгого вида наказания в виде лишения свободы, предусмотренного соответствующей статьей Особенной части УК (ч. 4 ст. 62 УК).

Как указывалось, когда присяжные заседатели вынесли вердикт о заслуживании лицом снисхождения за преступление, по закону караемое пожизненным лишением свободы или смертной казнью (ст. 65 УК), эти виды наказаний не применяются, а наказание назначается в пределах санкции, предусмотренной статьей Особенной части УК. Этим наказанием является лишение свободы на определённый срок, и его суд вправе определить и на максимальный срок, то есть 20 лет. Здесь правило смягчения наказания проявляется в запрете назначения пожизненного лишения свободы или смертной казни.

При совершении приготовления или покушения на преступление смертная казнь и пожизненное лишение свободы не назначаются (ч. 4 ст. 66 УК). Никаких уточняющих правил о назначении наказания при наличии в санкции статьи пожизненного лишения свободы или смертной казни закон не содержит. Судебная практика пошла по пути применения к лицу льготы дважды. Сначала не назначается пожизненное лишение свободы и смертная казнь, а затем лишение свободы определяется на срок не свыше половины (в случаях приготовления) или трех четвертей (при покушении) максимального срока или размера наиболее строгого вида наказания, предусмотренного статьей Особенной части УК за оконченное преступление.

При применении правила, закреплённого ч. 5 ст. 62 УК, вопрос о наказании в виде пожизненного лишения свободы и смертной казни не возникает. Как уже указывалось, согласно ч. 1 ст. 314 УПК особый порядок принятия судебного решения возможен только за преступления, наказание за которые, предусмотренное УК, не превышает 10 лет лишения свободы.

Федерации от 2 февраля 1999 года № 3-П по делу о проверке конституционности положений статьи 41 и части третьей статьи 42 УПК РСФСР, пунктов 1 и 2 Постановления Верховного Совета РФ от 16 июля 1993 года «О порядке введения в действие Закона Российской Федерации «О внесении изменений и дополнений в Закон РСФСР «О судоустройстве РСФСР», Уголовно-процессуальный кодекс РСФСР, Уголовный кодекс РСФСР и Кодекс РСФСР об административных правонарушениях» // Вестник Конституционного Суда РФ. 2011. № 2.
Разное законодательное решение о применении или невозможности применения обязательного смягчения наказания в рассмотренных ситуациях получило неодинаковую реакцию. А.С. Жумаевым высказано суждение о необходимости установления единых правил назначения или неназначения пожизненного лишения свободы и смертной казни ${ }^{7}$. Обосновывается, что разное решение этого вопроса объясняется различными основаниями для обязательного смягчения наказания

В этом вопросе предпочтительнее мнение А.C. Жумаева. Одним из аргументов является то, что в первоначальной редакции УК правила обязательного смягчения наказания предусматривали одинаковое положение. Оно было следующим: если статьей Особенной части УК предусмотрены пожизненное лишение свободы или смертная казнь, эти виды наказания не применяются (ч. 1 ст. 65 УК в ред. ФЗ от 13 июня 1996 г. «Уголовный кодекс Российской Федерации»; ч. 4 ст. 66 УК).

В ст. 62 УК в ред. ФЗ от 13 июня 1996 г. «Уголовный кодекс Российской Федерации» правило обязательного смягчения наказания при наличии смягчающих обстоятельств вообще не содержало положения о пожизненном лишении свободы и смертной казни. Однако в судебной практике при наличии смягчающих обстоятельств, предусмотренных п. «и» или «К» ч. 1 ст. 61 УК, и использовании правила, закрепленного ст. 62 УК, анализируемые наказания не применялись, а лишение свободы на определённый срок назначалось не свыше срока, определённого правилами, установлёнными в ст. 62 УК․ Таким образом, в первые годы действия УК правило о неназначении пожизненного лишения свободы и смертной казни было единым для всех видов обязательного смягчения наказания, предусмотренных ст. 62, 65, 66 УК. На наш взгляд, и в действующем уголовном законодательстве предпочтительнее аналогичный подход.

В норме по обязательному усилению наказания, предусмотренной ст. 68 УК, установлено, что срок наказания при любом виде рецидива преступлений не

\footnotetext{
${ }^{7}$ См.: Жумаев А.С. Специальные правила назначения наказания за единичное преступление. Автореф. дис...канд. юрид. наук. М., 2009. С. 1, 5, 9 и др.

${ }^{8}$ См.: Иногамова-Хегай Л.В. Современные проблемы назначения и освобождения от наказания в российском уголовном праве // The fourth session of the international forum on crime and criminal law in the global era. 2012 12.1-3. Supplementary Edition. Beijing China. 2012. C. 69.

${ }^{9}$ См.: Изменение приговора П. / Обзор судебной практики Верховного Суда РФ «Обзор кассационной практики Судебной коллегии по уголовным делам Верховного Суда Российской Федерации за 2007 г.» // СПС КонсультантПлюс. Судебная практика.
} 
DOI: $10.7256 / 1811-9018.2013 .12 .9942$

При цитировании этой статьи сноска на dоі обязательна

\section{Право и политика 12 (167) • 2013}

может быть менее одной третьей части максимального срока наиболее строгого вида наказания, предусмотренного за совершенное преступление, но в пределах санкции соответствующей статьи Особенной части УК. Указание закона об определении назначаемого наказания в рамках санкции статьи УК имеет важную смысловую нагрузку. Оно не позволяет в тех случаях, когда в санкции имеется нижний предел наказания, выйти за его границы.

Вместе с тем в специальных правилах обязательного смягчения наказания, предусмотренных ч. 1, 2, 5 ст. 62 , ст. 65 , ст. 66 УК, такого ограничения не установлено. По нашему мнению, отсутствие данного ограничения является пробелом закона, который возможно восполнить, предусмотрев в названных статьях правило, аналогичное положению, имеющемуся в норме о назначении наказания при рецидиве.

\section{Библиография:}

1. Агапов П.В. Досудебное соглашение о сотрудничестве как средство повышения эффективности противодействия организованной преступной деятельности // уголовное право: стратегия развития в XXI веке: материалы IX международной научно-практической конференции (26-27 января 2012). М., 2012. С. 96-97.

2. Иногамова-Хегай Л. В., Комиссаров В.С., Рарог А.И. Российское уголовное право. Общая часть / под ред. Л.В.Иногамовой-Хегай, Комиссарова В.С., Рарога А.И. М., 2011. С. 396.

3. Жумаев А.С. Специальные правила назначения наказания за единичное преступление. Автореф. дис...канд. юрид. наук. М., 2009. С. 1, 5, 9 и др.
4. Иногамова-Хегай Л.В. Современные проблемы назначения и освобождения от наказания в российском уголовном праве // The fourth session of the international forum on crime and criminal law in the global era. Beiging China. 2012. С. 69.

5. Разумов С.А. Комментарий к Уголовному кодексу Российской Федерации / отв. ред. В.М. Лебедев (автор - С.А. Разумов). М., Юрайт. 2004. С. 187.

\section{References (transliteration):}

1. Agapov P.V. Dosudebnoe soglashenie o sotrudnichestve kak sredstvo povysheniya effektivnosti protivodeistviya organizovannoi prestupnoi deyatel'nosti // ugolovnoe pravo: strategiya razvitiya v XXI veke: materialy IX mezhdunarodnoi nauchno-prakticheskoi konferentsii (26-27 yanvarya 2012). M., 2012. S. 96-97.

2. Inogamova-Khegai L. V., Komissarov V.S., Rarog A.I. Rossiiskoe ugolovnoe pravo. Obshchaya chast' / pod red. L.V.Inogamovoi-Khegai, Komissarova V.S., Raroga A.I. M., 2011. S. 396.

3. Zhumaev A.S. Spetsial'nye pravila naznacheniya nakazaniya za edinichnoe prestuplenie. Avtoref. dis...kand. yurid. nauk. M., 2009. S. 1, 5, 9 i dr.

4. Inogamova-Khegai L.V. Sovremennye problemy naznacheniya $\mathrm{i}$ osvobozhdeniya ot nakazaniya $\mathrm{v}$ rossiiskom ugolovnom prave // The fourth session of the international forum on crime and criminal law in the global era. Beiging China. 2012. S. 69.

5. Razumov S.A. Kommentarii k Ugolovnomu kodeksu Rossiiskoi Federatsii / otv. red. V.M. Lebedev (avtor - S.A. Razumov). M., Yurait. 2004. S. 187. 